\title{
Catalytic Carbon Submicron Fabrication Using Home- Built Very-High Frequency Plasma Enhanced Chemical Vapour Deposition
}

\author{
Sukirno ${ }^{1}$, Satria Zulkarnaen Bisri ${ }^{1,2}$, Rasih Yulia Sari ${ }^{1}$, Lilik Hasanah ${ }^{1,3}$, Mursal $^{1,4}$, \\ Ida Usman ${ }^{1,5}$ \& Darsikin ${ }^{1,6}$ \\ ${ }^{1}$ Laboratory for Electronic Material Physics, Faculty of Mathematics and Natural \\ Sciences, Institut Teknologi Bandung, Bandung 40132, Indonesia \\ ${ }^{2}$ Institute for Material Research, University of Tohoku, Japan \\ ${ }^{3}$ Department of Physics, Universitas Pendidikan Indonesia, Bandung 40154, Indonesia \\ ${ }^{4}$ Department of Physics, Universitas Syiah Kuala, Banda Aceh, Indonesia \\ ${ }^{5}$ Department of Physics, Universitas Haluoleo, Palu, Indonesia \\ ${ }^{6}$ Department of Physics, Universitas Tadulako, Kendari, Indonesia \\ Contact e-mail: sukirno@fi.itb.ac.id
}

\begin{abstract}
In this research, carbon nanotubes (CNT) fabrication has been tried by using an existing home-made Plasma Enhanced Chemical Vapour Deposition (PECVD) system. The fabrication is a catalytic growth process, whereby a $\mathrm{Fe}$ catalyst thin film is grown on the Silicon substrate by using $d c$-Unbalanced Magnetron Sputtering. Methane $\left(\mathrm{CH}_{4}\right)$ as carbon source and diluted silane $\left(\mathrm{SiH}_{4}\right)$ in hydrogen as hydrogen source (ratio 10:1) was used for the CNT fabrication with the Very High Frequency PECVD (VHF-PECVD) method. The fabrication process was executed at the relatively low temperature of $250^{\circ} \mathrm{C}$, but with the higher operating plasma frequency of $70 \mathrm{MHz}$.

Recently, a fabrication process with only a single gas source has been carried out as well, but using a modified VHF-PECVD system with an additional hot-wire component. The attempt was done at an higher growth temperature of $400^{\circ} \mathrm{C}$. Morphological characterizations, by using Scanning Electron Micrograph (SEM) and Scanning Probe Microscopy (SPM), and composition characterization, by using Energy Dispersion Analysis by X-Ray (EDAX), show convincing results that there are some signatures of CNT present.
\end{abstract}

Keyword: $250^{\circ} \mathrm{C} ; 70 \mathrm{MHz}$; dc Unbalanaced Magnetron Sputtering; fabrication of CNT by VHF PECVD.

\section{$1 \quad$ Introduction}

Since its first discovery by Iijima in 1991 [1], CNT has become attention for many researchers, especially for those working in the field of nano-science. The nature of CNT as nano-structured materials, where the properties depend on its atomic interaction as well as its structure, give CNT extraordinary unique properties that have never been found in the other materials. This leads to many new applications, which could be developed from CNT, in many fields,

Received December $28^{\text {th }}, 2007$, Revised August $25^{\text {th }}, 2008$, Accepted for publication September $15^{\text {th }}, 2008$ 
including in nano-electronic devices, super-strong materials, medicine and renewable energy applications.

From the electronic properties point of view, CNT is a very different material since it could appear as semiconductor and as metallic material. It depends on a so-called chirality's, the way how the nano-tube is wrapped into a cylindrical hollow shape. In analogy, there are so many ways to wrap paper to become a cylinder shape. This uniqueness makes the possibility of future development in CNT-based electronic devices.

There are many existing technique to fabricate CNT, based on either a top-down or a bottom-up process. Different techniques will result in different characteristics of CNT, which is not only limited to the structure of the nanotube itself that could become a single-walled nano-tube (SWNT) or a multiwalled nano-tube (MWNT), but also to other differences in the nano-tube properties. The top-down process generates CNT from conventional carbon solid target, such as graphite, by vaporizing the carbon atom from the targets at very high temperature. This kind of fabrication methods, which are mostly used, are arc discharge and laser ablation. Only limited SWNT will yield from this method. Most of the results are MWNTs. On the other hands, some attempts to dope the targets with metal catalysts was difficult to achieve.

The other common methods, which are bottom-up processes, are the Chemical Vapour Depositions (CVDs). By using the CVD process, the yielded CNT are mostly SWNTs, which are very useful for nano-electronic devices. Meyyappan [2] has reported that a CNT, which is grown by Plasma Enhanced Chemical Vapour Deposition (PECVD) at temperatures of $600^{\circ} \mathrm{C}-800^{\circ} \mathrm{C}$, is a high quality aligned nano-tube. Since the growth of the nano-tube itself is a catalytic process, there should be a catalyst deposition before the CNT growth is conducted.

In this paper, the CNT fabrication is reported by using a modified PECVD method, which is the VHF-PECVD that operates at higher plasma frequency. This is a part of the research for developing CNT-based nano-electronic devices in ITB. By operating at higher frequency, it is expected that there might be a difference of the yielded CNT properties, compared to the result of the conventional PECVD method. It is also expected that the CNT growth process could be done at a lower growth temperature. This paper explains the experimental steps. It concerns the catalyst deposition process by using the $d c$ UBMS method, and the CNT fabrication by using the VHF-PECVD method. The characterization results will be shown by using Scanning Electron Micrograph (SEM), Energy Dispersive Analysis by using X-Ray (EDAX) as 
well as Scanning Probe Microscopy (SPM). Finally, some theoretical perspective of CNT growth process will be reviewed.

\section{Experimental Method}

The growth of CNT itself is a catalytic process. A substance is required as trigger of the probe which will initiate and guide the growth process. The needed catalyst is a transitional metal, such as $\mathrm{Fe}, \mathrm{Ni}, \mathrm{Mo}, \mathrm{Mn}, \mathrm{Co}$ as well as $\mathrm{Pt}$ [3]. This transition metal catalyst must be present in every CNT growth process. For CVD process, the metal catalyst must be deposited first on the substrate before the growth of carbon nano-tube can precede.

The metal catalyst is deposited on the silicon (100) wafer substrate by using $d c$ Unbalanced Magnetron Sputtering ( $d c$-UBMS). This method is a type of Physical Vapour Deposition (PVD), where a target material is bombarded by some energetic ions or atoms, thus the atoms of the target material will be evaporated and physisorbed on the substrate which is placed opposite the target material.

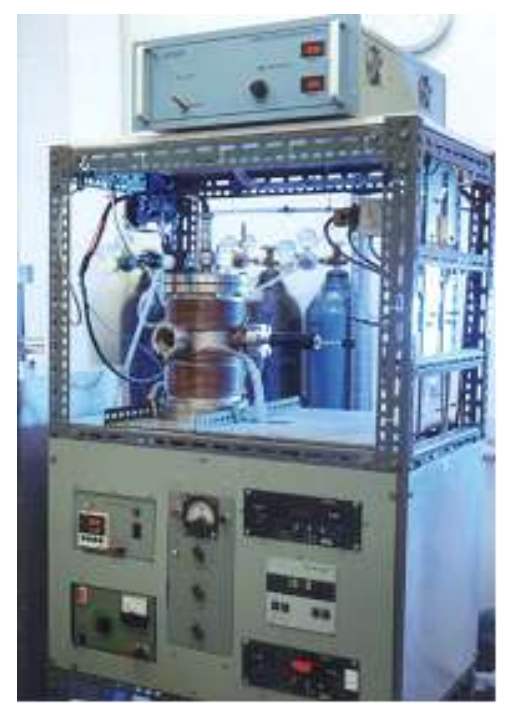

Figure 1 The existing home-made $d c$-UBMS system for metal catalyst deposition.

The Fe target is made from Fe powder. There are two Fe targets made. The first one is made from raw $\mathrm{Fe}$ powder, which is grinded manually for 4 hours and then pressed with $3 \times 10^{8} \mathrm{~Pa}$ pressure. Afterwards, it is sintered at $750^{\circ} \mathrm{C}$ for 2 hours at atmospheric condition. 
From the deposition parameter optimization, it has been found, that the Fe thin film will be deposited homogeneously under certain conditions. The sputtering process was performed at a growth temperature of $400^{\circ} \mathrm{C}$ with the base pressure of $1.6 \times 10^{-2-}$ Torr and a deposition pressure of $5.4 \times 10^{-2}$ Torr. As feeding gas Argon was used with a flow of $100 \mathrm{sccm}$. It is a non-reactive gas, but able to transfer enough momentum to the target material. A voltage of 600 volt $d c$ is applied for the glow discharge, which results in a current as big as $0.024 \mathrm{~A}$; therefore, the Argon plasma power is about 14.4 watt. The sputtering process was performed in 3 hours.

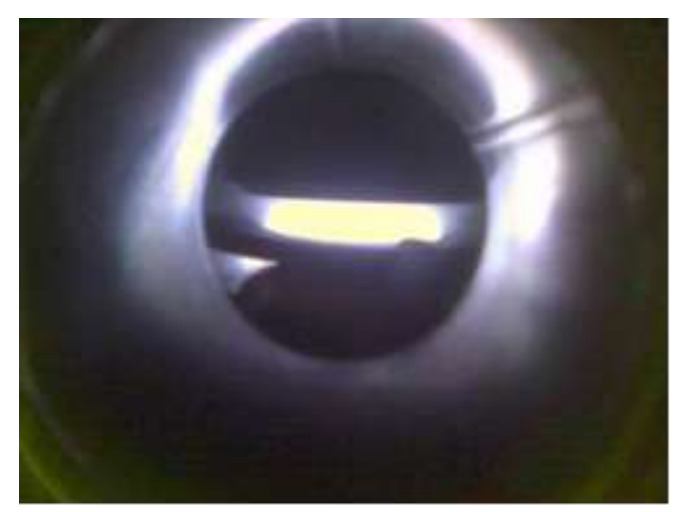

Figure 2 Glow discharge of Argon Plasma in Fe Catalyst Deposition Process.

The catalyzed substrates for the second type of the CNT fabrication process are post-treated differently. After the deposition process and a storage for more than 2 weeks, the substrates are post-annealed before they were used for the CNT fabrication with the PECVD. The post-annealing treatment is conducted at $600^{\circ} \mathrm{C}$ for 30 minutes in Argon atmosphere using a programmable electric furnace.

The growth of CNT by using CVD-type process must be sourced from carbonrich gases with some aid of hydrogen presence. Most of the researchers use ethylene $\left(\mathrm{C}_{2} \mathrm{H}_{2}\right)$ as the source gas or methane $\left(\mathrm{CH}_{4}\right)$ with some addition of hydrogen gas $\left(\mathrm{H}_{2}\right)$. For this research pure methane $\left(\mathrm{CH}_{4}\right)$ as the source of the carbon atoms and $10 \%$ diluted silane in hydrogen as the source of the hydrogen is applied. For another part of the research only the pure methane is used. 


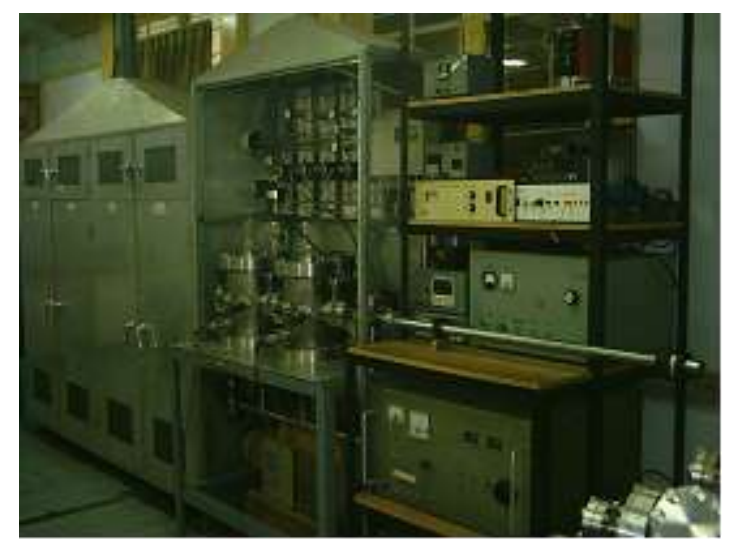

Figure 3 An existing PECVD system which is used for this research.

An existing home-made PECVD system is used in this research. It is a doublechambered PECVD system, which is equipped with a high vacuum pump, which can achieve $10^{-4}$ Torr of ultimate pressure.

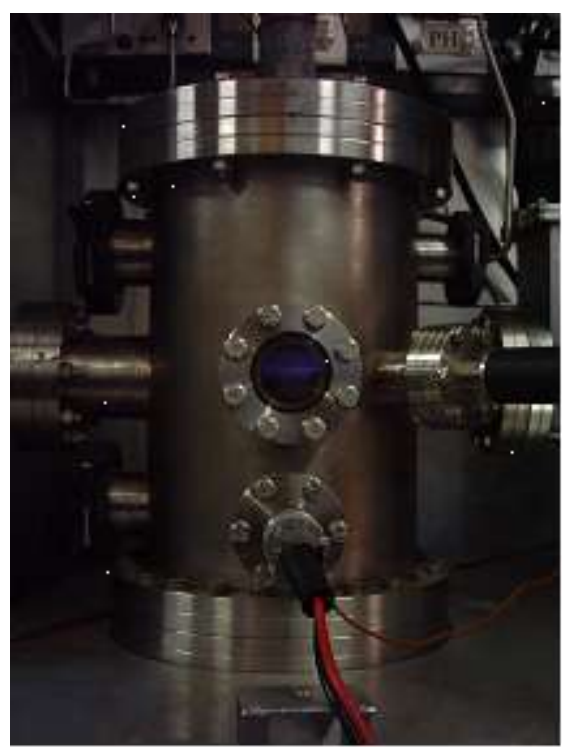

Figure 4 The glow-discharge plasma of PECVD which is use to grow CNT.

The first fabrication process is done using two gas sources, methane and $10 \%$ diluted silane, with a ratio of 10:1. For the fabrication process some parameters are set as default and some other parameters are varied. The growth temperature for this fabrication is $250^{\circ} \mathrm{C}$, which is relatively low for CNT fabrication. The 
chamber pressure is set to be $400 \mathrm{mTorr}$ during the fabrication, with $100 \mathrm{sccm}$ methane is flown as well as $10 \mathrm{sccm}$ diluted silane. In this fabrication process, the applied plasma frequency is $70 \mathrm{MHz}$, which makes this fabrication process a VHF-PECVD rather than a conventional PECVD, which is usually allies 13.56 $\mathrm{MHz}$ plasma frequency. The plasma power is varied in 4 different values from 20 watt up to 50 watt. This process is performed in 80 minutes growing time.

It has been tried to use the standard RF PECVD method (13.56 MHz) with an increase of the plasma temperature by a hot wire. However, the parameter optimization process for growing $\mathrm{SiC}$ on the Corning Glass substrate with desired gas ration (10:1) showed, that the silicon atoms became more reactive than carbon atoms. As a result, the silicon is more dominant than the carbon in the dummy thin film. Consequently it has been decided to use VHF PECVD to increase the plasma activity instead of using hot wire to increase the plasma temperature.

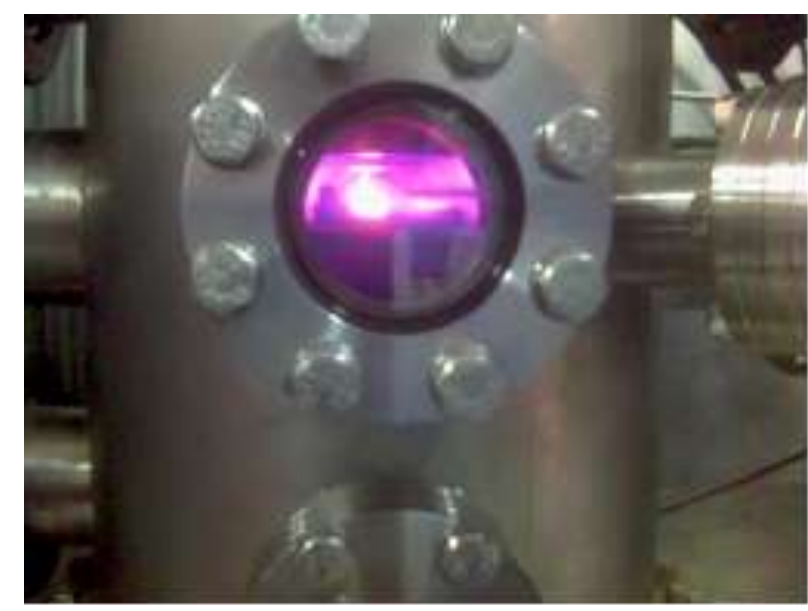

Figure 5 The plasma glow discharge of PECVD system when the hot wire filament is turned on for the CNT deposition.

The other experiment is the first attempt to grow CNT by using only one gas source, which is methane. The growth process is performed with a slightly higher growth temperature as the previous experiment, which is $400^{\circ} \mathrm{C}$, but which is still lower than the usual growth temperature to grow CNT. Since the presence of hydrogen radicals are needed in the growth process of CNT, the methane must pass a hot wire component before flowing into the reaction chamber. The purpose of hot wire presence is in order to decompose some of the methane and produce enough amounts of hydrogen radicals, while the rest of the methane will be decomposed by PECVD process to give the carbon 
radicals. This fabrication process was then designated as Hot-Wire-VHFPECVD (HW-VHF-PECVD) process. This process is performed at 400 mTorr deposition pressure with $100 \mathrm{sccm}$ methane flow into the reaction chamber. On the other hand, the plasma frequency is $70 \mathrm{MHz}$, which is still in the VHF region, while the plasma power is 50 watt. The hotwire temperature, which is use to pre-decompose the methane, is about $800^{\circ} \mathrm{C}$. The deposition process takes 45 minutes of time.

\section{Morphological Characterization, Results and Discussions}

The characterization of the samples are conducted by using Scanning Electron Micrograph (SEM), which is performed at $10 \mathrm{keV}$ and $20000 \mathrm{x}$ magnification, to observe the morphological structure of the samples and to find any submicrostructure; furthermore, any near nanostructure. The Energy Dispersion Analysis using X-Ray (EDAX) is also used in order to measure the substantial composition of the samples. All of the characterizations are performed using the available facility of the Quarternary Laboratory - Pusat Penelitian Geologi dan Kelautan (PPGL) -Bandung. For the sample, which is grown by only single gas source, and its catalyzed substrate, there is an additional characterization that has been made. It is by using Scanning Probe Microscopy (SPM), which in this case is using Atomic Force Microscopy (AFM) in semi-contact mode.

As a result of $\mathrm{Fe}$ catalyst growth, it is obtained a $\mathrm{Fe}$ thin film on silicon substrate. From the SEM image in Figure 6, it could be seen that the form of the Fe film is not homogeneous enough to become big crystalline structure. However, the Fe thin film become grain shaped. This result is the one desired for the CNT growth process. The grain shaped of Fe will become the probe of the CNT growth.

From the EDAX result, it is obtained that the percentage of the Fe atoms is only $15.94 \%$, and the other is silicon. With there is no possibility for the presence of silicon thin film, all of the silicon signature comes from the substrate. It could be inferred that the formed $\mathrm{Fe}$ layer is thin enough so the X-ray from the EDAX apparatus could go through until the silicon substrate. It also means that the deposition rate of Fe catalyst is very low since it take 180 minutes is needed for the deposition. This is due to the low plasma power during the sputtering process. However, the very thin layer is the one needed for CNT growth since it will only use as probe and evaporated, theoretically, after the CNT deposition process is over.

The post-annealed substrate is also characterized by using SEM, as shown in Figure 7. It could be perceived that the size of the grain become smaller. It is also confirmed from the AFM image of the post-annealed catalyzed substrate. 
From this image, it could be counted statistically by using Gwyddion image processor (by edge-detection method) that the average grain size of this catalyst is $82 \mathrm{~nm}$. It means that the post-annealing process of the catalyzed substrate is expected to decrease the size of the Fe catalyst grain.

From the SEM images it could be concluded, that submicron structures were formed on the silicon substrate. They are in granule form with various diameters, but less than $1 \mu \mathrm{m}$. From the cross section SEM images, the lengths of granules are also not more than $1 \mu \mathrm{m}$. From the statistic counts, which were done using Gwyddion image processor, the average grain size of granules could be counted, as tabulated in Table 1. It could be deducted, that the plasma power variations does not directly affect the grain size. However, the structures obtained have not shown any nano-tube presence since the tubular shape forms, which appeared in SEM images, are still too big to be considered as a nanotube. There is a possibility to obtain granules, which have diameters less than $100 \mathrm{~nm}$. From the surface SEM images, it could be seen, that the diameters of granules varying even in a similar sample. However, this could not be detected due to the magnification limitation of SEM apparatus as well as because of the samples, which are still dominated with larger granules.

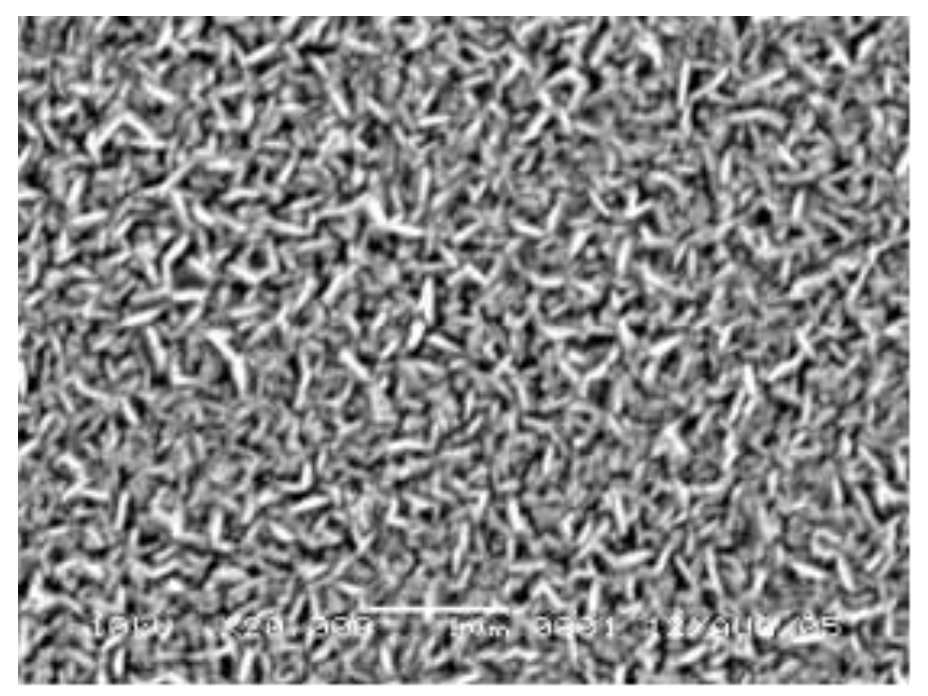

Figure 6 SEM image of Fe catalyst thin film on silicon substrate. 


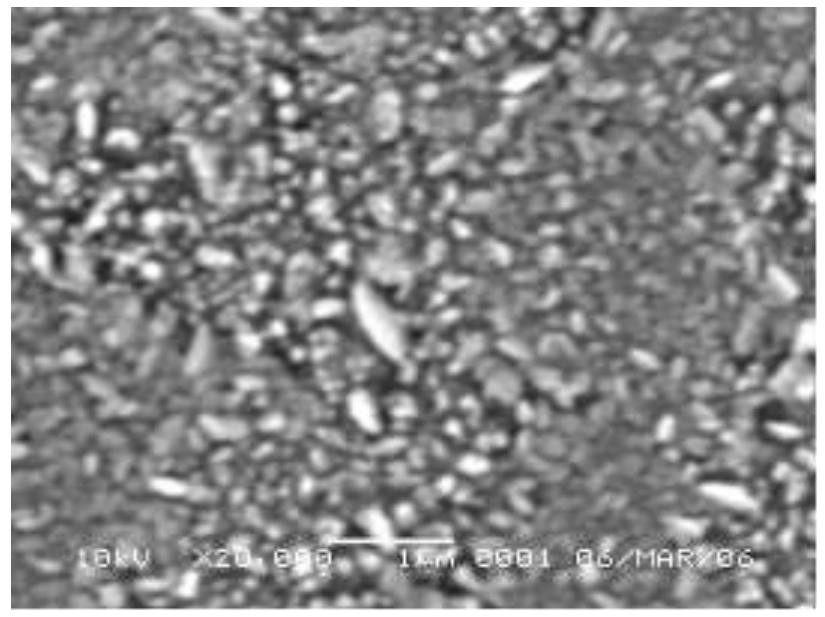

Figure 7 SEM image of post-annealed catalyzed substrate.

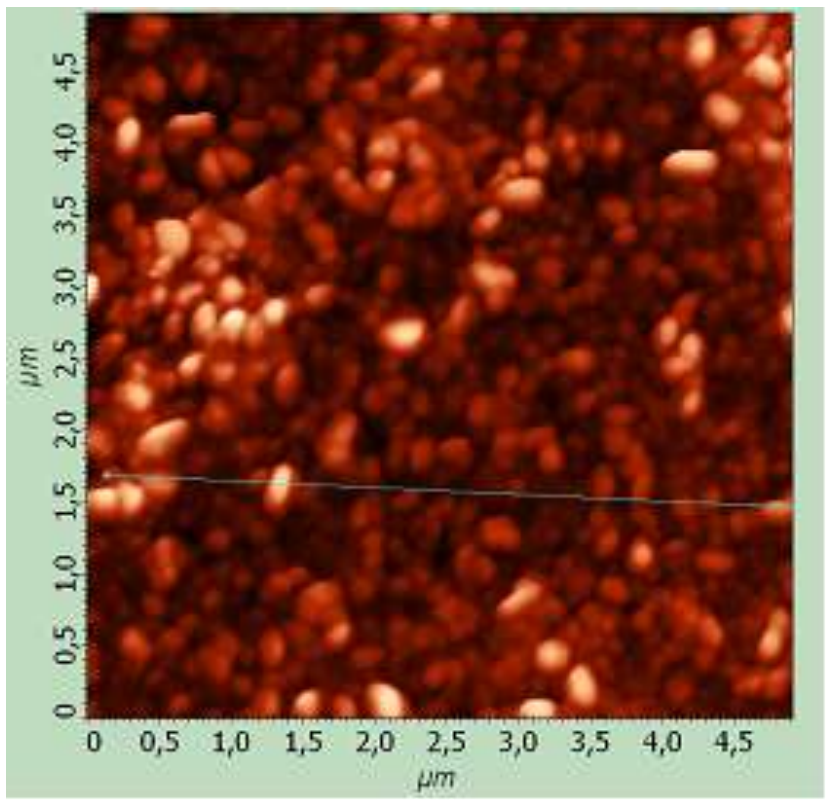

Figure 8 The AFM image of the catalyzed substrate.

From the EDAX characterization, the results show the relative composition of the thin film. The EDAX characterizations were performed when the SEM magnification is $2000 \mathrm{x}$ in order to have larger area. There are 4 substances which are measured using EDAX for this thin film. They are carbon, silicon, oxygen and iron, since those are the substances which would possible appear in 
the thin film. The results are tabulated in Table 2. From this characterization, it could be observed, that there is no correlation between plasma power and carbon percentage. However, this results show that the formed thin film are dominated by carbon. The presence of Silicon is mostly because the X-Ray penetrates through the silicon substrate, while there might be some other silicon which become defects on the thin film, since silane is used, or become Silicon oxide on some area where the structure is not grown. The growth mechanism itself has been already shown from the EDAX result where the percentage of the Fe is extremely decreasing compared with the one in the catalyzed substrate characterization. It might be remains as the $\mathrm{Fe}_{2} \mathrm{O}_{3}$, since there still some amount of oxygen, or at the tip of the structure itself. The possibility of oxide presence is because there might be some little contamination during the transfer process from the Oxide laboratory, where the $d c$-UBMS system is, to the PECVD laboratory. These EDAX measurement results are performed in relatively small errors, which all errors for all substance are less than $1 \%$, except for the Fe, which is about $2 \%$. These results are convincing that the structures grown are carbon materials. If they were not nano-tubes, they could become nano-rods.

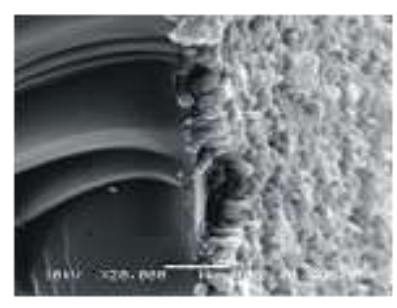

(a)

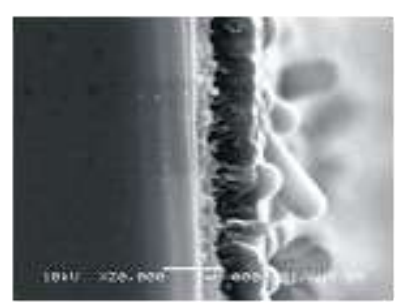

(c)

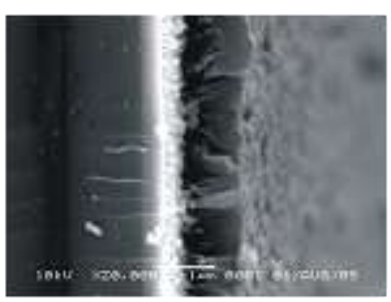

(b)

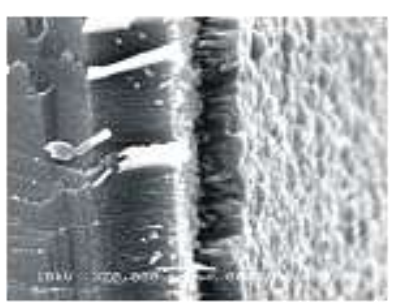

(d)

Figure 9 Cross-sectional SEM images (in $20000 \mathrm{x}$ magnification) of samples which grown by VHF-PECVD with variation of plasma power (a) $20 \mathrm{~W}$, (b) $30 \mathrm{~W}$, (c) $40 \mathrm{~W}$, (d) $50 \mathrm{~W}$. 


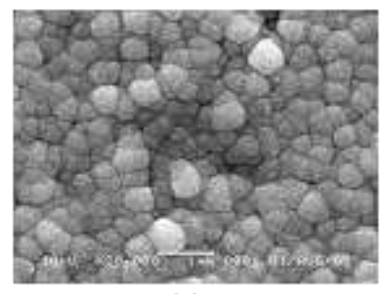

(a)

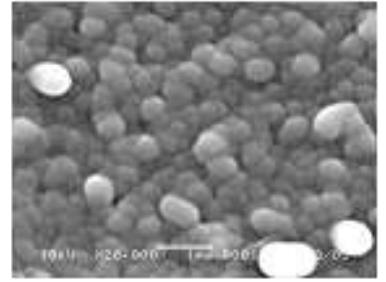

(c)

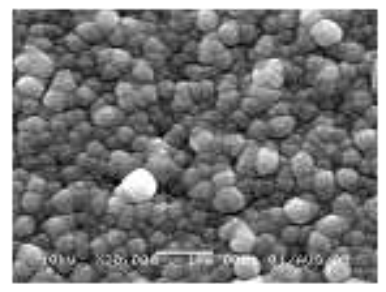

(b)

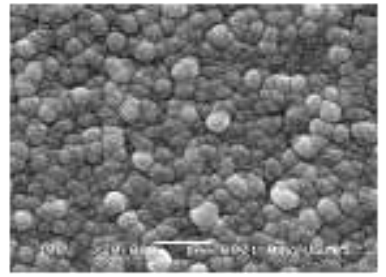

(d)

Figure 10 Surface SEM images (in $20000 \mathrm{x}$ magnification) of samples which grown by VHF-PECVD with variations of plasma power (a) $20 \mathrm{~W}$, (b) $30 \mathrm{~W}$, (c) $40 \mathrm{~W}$, (d) $50 \mathrm{~W}$.

Table 1 Average Grain diameters of samples which grown by VHF-PECVD for plasma power variations.

\begin{tabular}{cc}
\hline Plasma Power & $\begin{array}{c}\text { Average Grain } \\
\text { Diameter }\end{array}$ \\
\hline 20 watt & $127.60 \mathrm{~nm}$ \\
30 watt & $154.35 \mathrm{~nm}$ \\
40 watt & $108.79 \mathrm{~nm}$ \\
50 watt & $137.66 \mathrm{~nm}$ \\
\hline
\end{tabular}

Table 2 EDAX Measurement result of samples which grown by VHF-PECVD for plasma power variations.

\begin{tabular}{ccccc}
\hline $\begin{array}{c}\text { Plasma } \\
\text { Power }(\mathbf{W})\end{array}$ & C & Composition in Atomic \% \\
\hline 20 & 52.08 & 43.55 & Fe & O \\
30 & 53.94 & 40.47 & 0.78 & 4.07 \\
40 & 56.25 & 37.22 & 0.75 & 4.82 \\
50 & 53.44 & 39.41 & 1.47 & 5.67 \\
\hline
\end{tabular}

The other sample, which is grown from single gas source and by using hot-wire filament, is also characterized by using SEM and EDAX; moreover, it is also characterized using the AFM. From the SEM image, which is shown in Figure 11 , it could be inferred that the grain size of this sample is much smaller 
compared with the samples which are grown only by using VHF-PECVD. The SEM apparatus has been pushed to the limit of its magnification, but since the grain size is smaller, the image becomes blurring. From the cross-sectional SEM image, it could be inferred that the thickness of the film or structure is 2 $\mu \mathrm{m}$. It is much thicker than the samples grown by VHF PECVD. It means that the growth rate is much faster than the VHF PECVD. It might be possible since the growth temperature is higher than the usage of hot-wire, which makes the plasma temperature also higher.

The EDAX composition measurement shows that there is only $31.43 \%$ of carbon atoms, $45.59 \%$ of silicon atoms, $12.30 \%$ of oxygen atoms and $10.68 \%$ of iron atoms. It means that the percentage of the carbon atoms decreases compared with those are grown by VHF PECVD. However, since there is no possibility that silicon comes as defect because of no silane is used in this process. Therefore could be concluded, that all silicon comes from the substrate. It also means that the atomic density of the carbon atoms in the structure is decreasing. There are two contrary things which occur: A thicker/longer structure is obtained and the atomic percentage of carbon is decreasing. It might be pre-concluded, that the structure becomes smaller in grain size, therefore it leave many unfilled areas among the structure, or the structure itself becomes tubular which hollow inside, therefore the density decreases. This might be a sign for nano-tube presences.

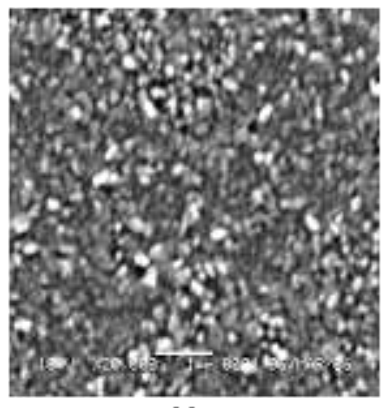

(2)

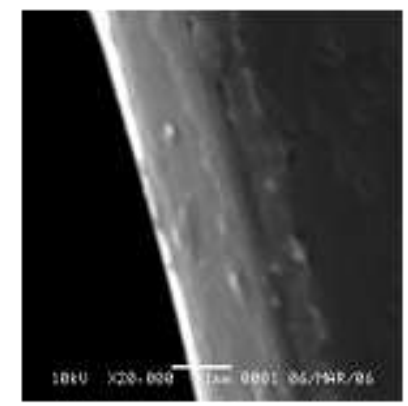

(b)

Figure 11 (a) Surface, (b) Cross-sectional SEM images of the sample which is grown by $\mathrm{HW}-\mathrm{PECVD}$ at $400^{\circ} \mathrm{C}$ growth temperature and single gas source, methane.

Another matter that happens is that the atomic percentage of the iron atoms is still big: $10.68 \%$, although the value decreased from $14.53 \%$, in the catalyzed substrate. It might be expected that a reason for the remaining big value are the many formed oxides, since the catalyzed substrate has been stored for a long time before it was post-annealed. Moreover, the post-annealing process itself 
did not remove all the oxide and might bind some of the Fe too tight to the substrate. The Iron oxide may not support the CNT growth since the presence of the oxygen in the oxide avoids the carbon atoms to bind to the iron atoms during the growth process. However, this EDAX results shows that the process leads to real CNT growth and some CNT structure formed.

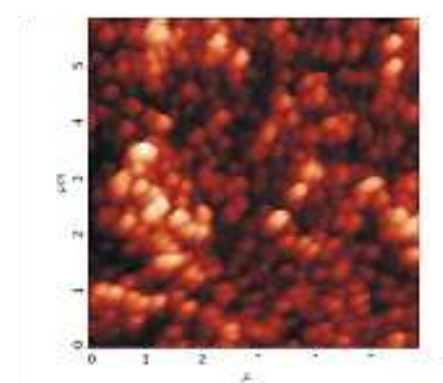

(a)

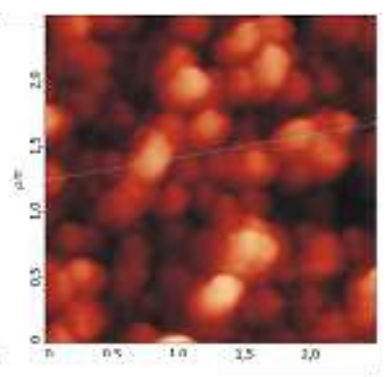

(b)

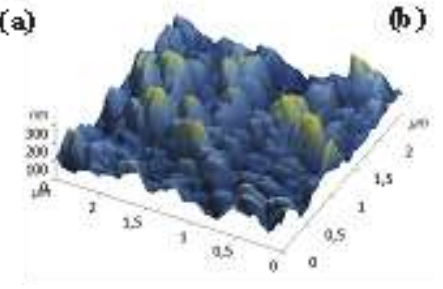

(c)

Figure 12 AFM scan images of samples which grown using HW-VHF-PECVD at $400^{\circ} \mathrm{C}$ growth temperature and single gas source, $\mathrm{CH}_{4}$. (a). $5 \mu \mathrm{m} \times 5 \mu \mathrm{m}$ scan size, (b). $2.5 \mu \mathrm{m} \times 2.5 \mu \mathrm{m}$ scan size, (c). 3-dimensional extrapolation of (b) result using Gwyddion image processor.

The AFM characterization shows much more revealing result. It was used an AFM with semi-contact mode, in order to avoid a braking of the AFM tip, since the structure might have a high-pillars shape. The size of the AFM tip was 20 $\mathrm{nm}$. The grain structure of the sample became clearer with higher resolution. The image has not confirmed any presence of nano-tubes, since the smallest scan size of the characterization is still too big: $2 \mu \mathrm{m} \times 2 \mu \mathrm{m}$, and a smaller scan size was yet not conducted. However, in some certain areas, there seem do be smaller structures present. They might form bundles with the others, which the AFM can only detect as one big granule. From the image processing the distance between the deepest trench and the highest peak was detected to be more than $300 \mathrm{~nm}$. However, the measured deepest trench is still not the actual deepest, only the deepest that could be observed by the tip. It is well possibility that there are even deeper trenches. The measurements seem to indicate the presence of some CNT, although it is not yet completely proven. 


\section{Theoretical Reviews on Carbon Nanotubes Growth Process}

In CNT growth process, a metal catalyst is used for its support. There are two possible mechanisms likely to happen. One theory says, that the catalyst acts as the root of the CNT [4,5] while the other says, that the catalyst become the top of the nano-tubes $[3,5]$. The first alternative states, that first $\mathrm{C}_{2}$ is bonded with the catalyst atom to the substrate and then triggers the next $\mathrm{C}_{2}$ to get bonded with the first $\mathrm{C}_{2}$ so the nano-tubes are grown with the catalyst remaining at the bottom. The second alternative states, that the catalyst sticks on the substrate and has an inverted pear shape. The $\mathrm{C}_{2}$ reaction only happens on the sharper surface of the catalyst, which is in the bottom side of the catalyst. The absorption of the other $\mathrm{C}_{2}$-s will cause the growth of the nano-tubes and the catalyst will rise up.

Feng Ding, et.al. [6] have investigated the second process by using molecular dynamics simulation. They state, that the catalyst dissociates the carbon rich gases, $\mathrm{CH}_{4}$ and produces in this way the required carbon atom. And then the carbon atoms dissolve into the catalyst particle while some other carbon atoms precipitate to the surface of the catalyst when supersaturated. These precipitated carbon atoms are nucleated into CNT. As a result it was concluded, that the diameter of the carbon nano-tubes are in the order of the diameter of the nanometer sized catalyst; the temperature gradient is not essential during the growth and the catalyst particle must be liquid.

From those explanations, it could be concluded, that the growth process of CNT has not been revealed microscopically. However, there are possibilities that during the growth process, the atom positions follows the pattern of the noncrystallographic Affine Coxeter Group Transfor-mation. The simulation result from Twarock, et.al. [7] shows almost similar results in carbon onion structures.

\section{Conclusions}

It has been tried to produce CNT by Plasma Enhanced Chemical Vapour Deposition at an operating frequency of $70 \mathrm{MHz}$, which is considered as Very High Frequency Plasma Enhanced Chemical Vapour Deposition. For the carbon supply a mixture of $\mathrm{CH}_{4}$ and diluted $\mathrm{SiH}_{4}$ as the feed gases has been used. The deposition temperature was still relatively low: $250^{\circ} \mathrm{C}$. The characterization results show the presence of carbon sub-microstructures, which still cannot be inferred as carbon nano-tube. The sub-microstructure itself appears as tubule shaped granules and from the EDAX results carbon as majority substance is detected. The growth process with hot-wire filament component, called HotWire VHF PECVD, brought some improvements. At a higher temperature $\left(400^{\circ} \mathrm{C}\right)$ growing some sign of carbon nano-tubes appeared. However, 
improvements are still needed in order to achieve consistent result as well as desired carbon nano-tubes for nano-electronic devices. The growth process itself is still a big question. It will become a most important question to be answered and it will have significant effects for future carbon nano-tube fabrication since many electronic devices need a chiral vector controlled carbon nano-tube.

\section{Acknowledgements}

This paper is a part of the Carbon Nano-Tubes Simulation and Fabrication Research phase I, which is funded by ITB Frontier Research Grant 2005 contract number 0076/K01.03/P12.1.5/VI/2005. The Authors also would like to acknowledge Mr. Wikanda from PPGL-Bandung for the SEM and EDAX characterizations. A grateful thank is also dedicated to Dr. Alexander Yaluvenko from NT-MDT, Russia, for the opportunity to use the Ntegra Scanning Probe Microscopy for characterizing the samples.

\section{References}

[1] Iijima, S., Nature (London) 354, 56, 1991.

[2] Meyyappan, M., Delzet, L., Cassell, A., Hash, D., Carbon Nanotube Growth by PECVD: a Review, Plasma Sources Sci. Technol, 12 (2003) 205-216, 2003.

[3] Saito, R., Dresselhaus, G. \& Dresselhaus, M.S., Physical Properties of Carbon Nanotubes. Imperial College Press, 1998.

[4] Daenen, M., et.al., Wondrous World of Carbon Nanotubes: A Review, TU Eindhoven, The Netherlands, 2003.

[5] Maiti, A., Brabec, C.J., Roland, C. \& Bernhole, J., Theory of Carbon Nanotube Growth, Phys. Rev. B, 5220 (1995) 14 850, 1995.

[6] Ding, F., Rosen, A., Bolton, K., Molecular Dynamics Simulation of Carbon Nanotube Growth, Presentation in NT'05 Conference, Sweden, 2005.

[7] Twarock, R., New Group Structures for Carbon Onions and Carbon Nanotubes via Affine Extention of Non-Crystallographics Coxeter Groups, arXiv: physics/0202042v1, 2002. 